\title{
Farda, saúde e etnia: a presença de populares negros na polícia de Porto Alegre através dos registros da Santa Casa de Misericórdia (1888 - 1894)
}

Livery, health and ethnicity: the presence of black folk in the Porto Alegre police force through the registries of Santa Casa de Misericórdia (1888 - 1894)

\author{
Giane Caroline Flores* \\ giane.flores@yahoo.com.br
}

Resumo: O trabalho se propõe a apresentar resultados preliminares de uma pesquisa sobre a presença de populares, especialmente os negros, nas instituições de controle urbano no período de transição entre Império e República na cidade de Porto Alegre/RS. Entre a documentação já analisada estão os registros de Matrícula Geral dos Enfermos da Santa Casa de Misericórdia de Porto Alegre, uma das poucas fontes que mantém a referência de cor dos indivíduos registrados, já que a partir do final do século XIX, com a abolição da escravidão e a República, há um desaparecimento gradual sobre a cor das pessoas que predomina em diversos registros históricos devido à tentativa de "embranquecimento" da população brasileira. Além disso, podemos retirar desta fonte importantes informações sobre os populares da cidade, como por exemplo: nome, data de nascimento, filiação, origem, estado civil, enfermidade, profissão e, como já citado, cor. Essa referência étnica presente nos registros analisados é fundamental para um estudo sobre a presença dos negros no período pós-abolição, sobretudo no que diz respeito à inserção dos mesmos no mundo do trabalho. Pretende-se analisar, portanto, o ingresso dessa parcela da população nas instituições de controle urbano como uma estratégia de ascensão social e também de defesa frente às perspectivas racistas vigentes no período, bem como outros aspectos de suas vidas como saúde e doença, relações familiares, entre outros.

Palavras-chave: polícia, trabalho, etnia

Abstract: This work seeks to present preliminary results of a research about the presence of popular classes, specially black people, in urban control institutions during the transition period between the Empire and the Republic in the city of Porto Alegre, Rio Grande do Sul. Among the analyzed documentation are the registries of General Registration of Infirms of the Santa Casa de Misericórdia de Porto Alegre, that is one of the few sources that keep the reference to the color of registered individuals, since by the end of the $19^{\text {th }}$ Century, with the abolition of slavery and the start of the Republic, there is a gradual disappearance of the color of people in historical registries due to the attempt of Whitening'the Brazilian population. Besides, it is possible to take away from this source some important information about the popular folk of the city, such as: name, date of birth, affiliation, place of origin, marital status, infirmity, profession, and, as cited above, color. This ethnic reference present in the analyzed registries is fundamental for a study about the presence of black people in the post-abolition period, especially about their insertion in the working world. This paper seeks to analyze, therefore, the ingress of this part of the population in the institutions for urban control as a strategy for social ascension and also as a means of defense in face of the racist perspectives that were current in the period, as well as other aspects of their lives, such as health and sickness, family relations, among others.

Keywords: police, work, ethnicity

*Mestranda em História pela Universidade do Vale do Rio dos Sinos (UNISINOS). 
Tempos de mudanças: a necessidade do controle

Sabemos que o final do século XIX é um período marcado por intensas mudanças na sociedade brasileira. A abolição do trabalho escravo em 1888 e a instauração da República em 1889 marcaram de forma especial a vida da população negra que buscava uma forma de inserção não só no mundo do trabalho livre como também em uma sociedade extremamente racista pautada nos estudos de eugenia, higienismo e darwinismo social ${ }^{1}$. Além disso, foi neste período que Porto Alegre iniciou um processo de urbanização e crescimento populacional devido à imigração (sobretudo de alemães e italianos), o aumento das ofertas de emprego e o fato da cidade tornar-se um centro comercial, como explica Sandra Pesavento (1990, p. 34-35):

O crescimento populacional de Porto Alegre deve-se, muito provavelmente, ao desenvolvimento do complexo colonial imigrante, no sentido de exportar alimentos e gêneros manufaturados simples para o mercado central cafeeiro. Em função da dinamização da cidade como centro comercial escoador da produção colonial, ampliaram-se as possibilidades de emprego dentro de uma economia que transitava para o trabalho livre.

Com estas transformações, o contexto econômico e social do país se modificou para tentar se adaptar a universalização do trabalho livre, a expansão da indústria e a crescente urbanização. Especialmente no Rio Grande do Sul onde as elites e os políticos republicanos se pautavam nos preceitos positivistas, foram colocados em prática os projetos que tinham como base a ideia de “ordem e progresso". Ainda segundo Sandra Pesavento
(1990, p.17), baseado nesses preceitos positivistas o governo republicano gaúcho entendia que "o progresso seria dado pelo desenvolvimento industrial, pelo primado da ciência, pela educação e pela moral”. Enquanto a educação e a moral garantiriam a ordem, a ciência e a indústria seriam responsáveis pelo progresso. Dessa forma, além de incentivar a educação e a ciência e criar propostas de defesa da indústria, a moral deveria ser estabelecida. Para isso as instituições que garantiriam o controle social ganharam papel relevante nos projetos republicanos que visavam, entre outras coisas, a manutenção da ordem, a segurança do território ${ }^{2}$ e a tranquilidade pública.

A preocupação do governo republicano com a guerra civil que eclodiu em 1893, foi responsável pelo maior investimento na segurança. Um exemplo disso foi a Brigada Militar, criada dentro do contexto de preparação para a Revolução Federalista, na qual durante dois aos e meio "se opuseram os castilhistas, ou picapaus, e os federalistas liderados por Gaspar Silveira Martins, chamados de gasparitas ou maragatos, que defendiam um modelo parlamentarista de governo e queriam a revisão da constituição estadual" (MAUCH, 2011, p. 38). Cláudia Mauch (2011, p. 39) salienta ainda que durante o período da guerra civil o Rio Grande do Sul viveu em um "estado excepcional" onde as Guardas Municipais serviram de forças auxiliares da Brigada Militar. Deve ser destacado ainda que, mesmo que a maior parte dos confrontos e batalhas da Revolução Federalista tenham ocorrido em regiões da fronteira, a guerra civil teve profundo impacto na capital gaú-

\footnotetext{
${ }^{1} \mathrm{O}$ termo eugenia foi criado pelo antropólogo inglês Francis Galton e designava o estudo dos agentes sob o controle social que poderiam melhorar ou empobrecer física ou mentalmente as qualidades raciais das próximas gerações. Sobre o assunto recomendo a leitura de: SCHWARCZ, Lilia Moritz. $O$ Espetáculo das raças: cientistas, instituições e questão racial no Brasil 1870 - 1930. São Paulo: Companhia das Letras, 1993.

${ }^{2}$ Cabe destacar que a Constituição estadual de 14 de julho de 1891, escrita por Júlio de Castilhos e baseada em preceitos positivistas, previa a "divisão de tarefas entre estado e município nas questões de segurança pública", como destaca Cláudia Mauch (2011, p. 37-38). Nesta divisão "à força pública caberia a função de manter a ordem, segurança e integridade do território sul-rio-grandense, ficando o policiamento dos municípios a cargo de guardas municipais subordinadas aos respectivos intendentes”. Essas guardas, com caráter militar, podiam ser incorporadas à força pública estadual em casos especiais, como ocorreu durante a Revolução Federalista (1893-1895). Devemos ainda lembrar, como cita Mauch, que a criação da Brigada Militar, em 15 de outubro de 1892, se deu como uma preparação do governo para o "conflito armado entre republicanos castilhistas e a oposição" que eclodiu no ano seguinte.
} 
cha uma vez que mobilizou contingentes policiais de todo o Estado. Entretanto, como já foi destacado, a intenção deste trabalho não é a de analisar a constituição da Brigada Militar e das Guardas Municipais como instituições do governo republicano. Por mais que este contexto seja importante para o desenvolvimento do trabalho, o foco aqui é compreender a inserção de indivíduos negros e pardos nestas instituições como uma alternativa de entrada no mundo do trabalho e também de ascensão social, em um período extremamente racista e socialmente hierarquizado.

Pensando neste contexto de uma sociedade racista, a polícia teve papel importante neste ponto, já que, além da guerra civil, outra questão que preocupava as elites era a inserção do negro, agora livre, na sociedade. Buscava-se uma alternativa que substituísse o chicote no controle dessa população vista como perigosa e como uma ameaça para a manutenção da ordem e do bem estar social. André Rosemberg salienta a preocupação das elites em manter a ordem após o fim da escravidão quando não mais se poderia controlar a população negra no espaço privado através do cativeiro:

O projeto de modernidade e de progresso passava inevitavelmente pela manutenção da ordem e da tranquilidade pública, isto é, demandava a transitividade para o espaço público das regras relacionais vigentes na esfera privada, por meio da substituição das estratégias tradicionais de poder - baseadas na dominação pessoal - por estratégias fundamentadas pela mediação de um agente impessoal e legitimado por lei. (ROSEMBERG, 2008, p. 15).
Dentro deste contexto, a polícia foi a alternativa mais adequada para o controle do espaço urbano e das chamadas classes perigosas ${ }^{3}$, compostas principalmente pela população negra recém-saída do cativeiro. A partir desse momento as instituições policiais passaram a assumir plenamente a autoridade de aplicar a lei e a ordem e disciplinar os espaços públicos, tarefa que antes era exercida pelas polícias provinciais junto a outras instituições como a Guarda Nacional. André Rosemberg (2008, p. 17) destaca a importância de se manter a população negra em "seu devido lugar" em uma sociedade hierarquizada, através de um mediador como a polícia:

Era a policia o mediador mais destacado para impor a nova ordem aos trabalhadores recém-desgarrados das peias da escravidão. Ao garantir a ordem social e a tranquilidade pública, a instituição asseguraria que cada indivíduo se mantivesse no lugar social que a ele estava atribuído no plano das aspirações dos poderosos.

Antes de refletirmos a respeito de quem eram os indivíduos que compunham o corpo policial algumas considerações a respeito da historiografia que aborda este tema devem ser realizadas. As pesquisas relacionadas ao crime e as instituições normativas, como a polícia, são relativamente recentes na historiografia brasileira e começaram a crescer na década de 1980 através do uso de fontes policiais e judiciárias. Essas pesquisas foram influenciadas pela história social inglesa (principalmente E. P. Thompson) e pela obra de Michel Foucault que recorreram a arquivos judiciais e policiais

\footnotetext{
${ }^{3}$ No Brasil, o conceito de classes perigosas, que teve origem na Europa na primeira metade do século XIX, logo se tornou uma espécie de sinônimo da população pobre, onde se encontravam os negros recém-saídos do cativeiro. Sidney Chalhoub explica como esse conceito foi introduzido no Brasil após o fim da escravidão, quando os deputados começaram a debater sobre as consequências da abolição na organização do trabalho e colocaram em pauta um projeto de lei de repressão à ociosidade, utilizando como fonte alguns autores franceses, entre eles M. A. Frégier, funcionário da polícia de Paris, que publicou em 1840 um livro sobre as classes perigosas onde procurava descrever os malfeitores de Paris. Contudo, neste estudo Frégier acaba descrevendo as condições de vida da população pobre da cidade em geral e "ele falhou na tentativa de determinar com qualquer precisão a fronteira entre as 'classes perigosas' e as 'classes pobres", fazendo com que as duas fossem vistas como sinônimos. (CHALHOUB, 1996, p. 21). Ver mais em: CHALHOUB, Sidney. Cidade Febril: Cortiços e epidemias na corte imperial. São Paulo: Companhia das Letras, 1996, p. 20-29; CHALHOUB, Sidney. Classes perigosas. Trabalhadores. Campinas: Associação Cultural do arquivo Edgard Leuenroth, n. 6, 1990.
} 
para produzir seus estudos da chamada "nova história cultural”. Como salienta a historiadora Cláudia Mauch (2007, p.108), a nível mundial, os trabalhos que tratam especificamente da história da polícia começaram a surgir nos anos 60. Alguns trabalhos pioneiros como o de Michael Banton (1969) desencadearam diversas pesquisas que tratavam do trabalho cotidiano do policial, considerando suas práticas e decisões do dia-a-dia nas atividades de manutenção da ordem e da paz.

Outra questão a se discutir refere-se a uma visão negativa e limitada sobre a polícia na historiografia, visão esta que é relatada por André Rosemberg e Marcos Bretas em artigo de 2013:

Do ponto de vista acadêmico, a polícia era subsumida em grandes esquemas explicativos, onde se fazia instrumento dócil. Numa perspectiva liberal, ela fazia parte das instituições do progresso moderno, parte pouco significativa da história de um Estado que se fazia melhor, mais racional e democrático. Numa perspectiva marxista, fazia parte do arsenal repressivo, agindo sob as ordens de um Estado ou de uma burguesia opressora. (BRETAS; ROSEMBERG, 2013, p. 163)

Dessa forma, em nenhuma das perspectivas destacadas pelos autores se considerava a individualidade dos policiais, pensando nesses sujeitos como seres portadores de certa autonomia sobre suas ações. Autonomia que certamente existia, já que eles possuíam relativa liberdade de decisão sobre suas práticas no cotidiano. A historiadora Cláudia Mauch (2007, p. 108) saliente que as atitudes, decisões e práticas cotidianas destes policiais, além de balizadas pela lei e pelos regulamentos da instituição, eram baseadas também pelas avaliações que estes indivíduos faziam das situações e dos sujeitos nelas envolvidos, colocando em prática seus próprios valores e interpretações, já que possuíam poder de escolha "na aplicação (ou não) da lei".

Nesse sentido, novos estudos sobre a história da polícia foram fundamentais para que a instituição poli- cial "deixasse de ser vista apenas como parte da administração pública ou 'braço armado' do Estado com funções previsíveis de repressão e imposição da lei” (MAUCH, 2007, p. 109). Destacamos alguns pesquisadores que ao enfatizarem a rotina do serviço da polícia deram atenção a figura do policial renovando a historiografia sobre o tema. Além dos trabalhos já citados de Cláudia Mauch (2004, 2011), André Rosemberg (2008) e Marcos Bretas (1997), podemos citar ainda as produções de Souza (2009) e Martins (2012) que abordam essa perspectiva.

Honrado, sadio e de bons costumes: o policial ideal no início da República

A historiadora Cláudia Mauch em sua tese de doutorado apresenta como problema central "o que era ser policial em Porto Alegre nas décadas iniciais da república brasileira". Uma das questões abordadas pela autora refere-se ao "modelo ideal" de policial que as elites buscavam. Dentro do pensamento do período, onde os populares (de forma especial negros e pardos) eram vistos como classes perigosas e o governo via na atuação da polícia a melhor forma de controle desta parcela da população, esperava-se que o policial fosse um bom trabalhador, com qualidades que o diferenciassem dos populares que ele deveria fiscalizar. O bom policial deveria ser: "[...] homem 'firme e enérgico sem violência', mas também 'honrado, de bons costumes, circunspecto e de maneiras delicadas', 'cortês e amável sem baixeza', que deveria se contrapor às maneiras 'incivilizadas e deseducadas' dos criminosos e turbulentos." (MAUCH, 2011, p. 31).

Essa imagem de "bom trabalhador" não se restringia apenas aos policiais. Os governos republicanos investiram na construção dessa imagem na busca de implantar no Brasil um padrão de trabalhador próximo aos europeus e aos ideais de civilização que gostariam de estabelecer no país. Para ser considerado um bom 
trabalhador era necessário não apenas ser um sujeito honesto, fiel, morigerado, saudável, mas também branco. Dessa forma, os trabalhadores nacionais, sobretudo os recém-saídos do cativeiro, não eram compatíveis com o padrão de trabalhador ideal buscado pelas elites que procurou "embranquecer" a população lhes negando a referência étnica e incentivando a vinda de imigrantes europeus.

Uma das consequências disso é o desaparecimento de dados sobre a cor nos documentos do período pós-abolição já que esse "embranquecimento" se estende às fontes. Contudo, não podemos atrelar o desaparecimento da referência étnica dos registros unicamente as elites brasileiras já que a própria comunidade negra passou a repudiar termos como negro ou preto durante certo período histórico, uma vez que estes os associavam a um passado recente ligado ao cativeiro, como ressalta Hebe Mattos (1995, p. 319):

$O$ desaparecimento da marca racial dos registros policiais não foi uma invenção republicana, mas uma prática já plenamente vigente, em relação aos homens nascidos livres, nas últimas décadas da escravidão, nas áreas analisadas. Perder o estigma do cativeiro era deixar de ser reconhecido não como liberto (categoria necessariamente provisória), mas como 'preto' ou 'negro', até então sinônimos de escravo ou ex-escravo e, portanto, referentes a seu caráter de não-cidadãos.

Ainda segundo Hebe Mattos, o desaparecimento da cor dos registros documentais se torna um grande empecilho para os pesquisadores do período pósabolição, especialmente no Brasil onde isto ocorre de forma mais acentuada:

[...] desde que os libertos deixam de ter um estatuto jurídico especifico, nas antigas sociedades escravistas, torna-se bem mais dificil encontrá-los nas fontes da época. Essa é uma dificuldade geral nas pesquisas sobre a experiência histórica pós-emancipação nas Américas. No Bra- sil, entretanto, é especialmente acentuada [...] pela presença demograficamente expressiva, e mesmo majoritária, de negros e mestiços livres, antes da Abolição e pelo desaparecimento, que se faz notar desde meados do século XIX, da discriminação da cor de homens e mulheres livres nos registros históricos disponiveis. Processos civeis e criminais, registros paroquiais de batismo, casamento e óbito, na maioria dos casos, não faziam menção à cor e, mesmo nos registros civis, instituidos em 1888, em muitos casos, ela se faz ausente. (MATTOS, 2013, p. 31).

Na já citada pesquisa de Cláudia Mauch, entre outras fontes, a autora analisou os registros de pessoal da Polícia Administrativa de Porto Alegre. Através desses registros ela realizou uma análise das informações encontradas nessas fontes e traçou um perfil socioeconômico dos homens que ingressavam na polícia da capital rio-grandense nas décadas iniciais da República. Dentre as informações coletadas por ela encontram-se: nome, data de entrada na polícia, nome do pai, idade, estado civil, nacionalidade, profissão e atestado de conduta. Os resultados obtidos pela historiadora (2011, p. 107) revelam que a maioria dos policiais ingressava na instituição com a idade média entre 21 e 30 anos, cerca de $64,12 \%$ eram registrados como solteiros e a maioria absoluta era de brasileiros. Quanto às profissões anteriores desses policiais, os dados coletados por Mauch (2011, p. 114) mostram que mais da metade desses indivíduos eram operários, jornaleiros, entre outras profissões humildes, sendo assim é seguro supor que se tratavam de trabalhadores pobres.

É interessante notar que não só nos registros estudados pela historiadora Cláudia Mauch, mas também nas fontes da Santa Casa de Misericórdia, muitos destes policiais apresentam outra profissão (ou uma profissão anterior) além do trabalho como policiais. Como nos Livros de Matrícula Geral dos Enfermos, utilizados para essa pesquisa, a ocupação dos pacientes como policias, praças, guardas cívicos ou guardas mu- 
nicipais, é encontrada no campo do documento destinado á classe, ou seja, a classe social/econômica ao qual o indivíduo pertenceria e que determinaria o pagamento ou não - dos serviços prestados pela Santa Casa; na maioria dos registros destes policiais o campo profissão fica em branco, o que pode ser entendido devido à possibilidade de para a maioria destes sujeitos a polícia ser a primeira forma de entrada no mundo do trabalho. Entretanto, em alguns registros, além da referência de classe, indicando que o paciente é policial ou guarda cívico, há também a referência à outra profissão exercida por ele antes do ingresso no serviço policial. Entre as profissões mais recorrentes encontram-se 13 carpinteiros, 10 pedreiros, 7 sapateiros, além de jornaleiros, pintores, padeiros, entre outras profissões destinadas a parcela mais humilde da população porto-alegrense. A partir disso podemos supor que para alguns desses indivíduos o trabalho na polícia era encarado como um serviço "temporário" e não uma carreira profissional a ser seguida, procurando se especializar em outras atividades como a carpintaria, por exemplo.

Retornando ao trabalho de Cláudia Mauch, um dado importante ficou de fora do levantamento realizado pela historiadora: a composição étnico-racial dos policiais. Isto porque essa informação não consta nos registros de pessoal da polícia administrativa de Porto Alegre, conforme ressalta a autora: "Na matrícula, não há menção sobre cor dos ingressantes, e como os brasileiros são esmagadora maioria, fica-se sem saber quantos dos policiais eram não-brancos ou se existia alguma preferência velada por brancos” (2011, p. 118). Isso possivelmente ocorre devido ao "embranquecimento" das fontes já citado anteriormente.
Esse desaparecimento da referência étnica dos registros é um empecilho que pode ser superado com o uso de fontes documentais alternativas como os Livros de Matrícula Geral dos Enfermos utilizados nesta pesquisa. Nestes livros eram registrados todos os indivíduos que procuravam a instituição em busca de atendimento. Entre as informações encontradas nesta fonte constam: nome, data de entrada na instituição, idade, naturalidade, filiação, profissão, estado civil, classe (forma como se dava o pagamento da instituição), enfermidade, data de saída e cor. Mesmo após 1888/89 a cor permanece sendo registrada nos registros da Santa Casa de Misericórdia possivelmente por este ser um fator importante para o pensamento médico na época, marcado pelas questões de eugenia e higienismo:

[...] a raça - foi tema de muitos textos de fundamentação higienista. Torna-se necessário discernir duas questões a ela relacionadas: o papel de determinações de natureza racial, ou étnica, na transmissão e no desenvolvimento de doenças, e [...] a importância do debate sobre inferioridade racial nos projetos para construir a nacionalidade. (HOCHMAN; LIMA, 2004, p. 505).

Cabe salientar que desde o último quartel do século XIX “o Rio Grande do Sul mostrava-se rigorosamente ligado aos debates intelectuais que grassavam no centro do país"4 sobre as questões de eugenia e higienismo. Os "homens de ciência" riograndenses incorporaram estes discursos na busca de "uma narrativa identitária que procurou no 'ser gaúcho' traços de superioridade/inferioridade racial em relação aos demais estados da união" (SILVEIRA, 2005, p. 124-125). Éder Silveira destaca que é possível notar a absorção destas ideias no discurso médico do Rio Grande do Sul através de uma

\footnotetext{
${ }^{4}$ Eder Silveira salienta que desde 1870 as teorias de cunho raciológico estiveram presentes nos discursos de diversos autores representativos do período, como Silvio Romero, Nina Rodrigues e Euclides da Cunha, que viam o Rio Grande do Sul como um local de desequilíbrio regional devido à imigração alemã. Para Silvio Romero através do cruzamento das "raças superiores", os alemães, e as "raças inferiores", negros e índios, se chagaria ao branqueamento racial e, consequentemente, ao melhoramento das raças. A miscigenação faria com que as gerações seguintes fossem "fortalecidas pelos elementos mais característicos das raças inferiores, como força física e resistência às adversidades do clima, preponderando, porém, os caracteres da raça superior, como a composição física e a cor branca". Dessa forma, devido ao alto número de habitantes da "raça superior", o Rio Grande do Sul "branquearia" rapidamente e ficara evolutivamente à frente das outras regiões do país. (SILVEIRA, 2005, p. 117).
} 
análise de fontes, como os jornais por exemplo. Segundo ele:

Uma análise superficial de publicações veiculadas pela imprensa local já dá conta da inserção do cientificismo, em especial no que tange ao discurso médico e criminológico, no cenário sul-riograndense. Além disso, a análise dos relatórios dos presidentes da província indica a recepção, no caso, por parte dos homens de estado das teorizações coetâneas sobre a necessidade de uma ação higienizadora sobre o espaço urbano, sobre a criminologia, ou sobre a questão racial no estado. (SILVEIRA, 2005, p. 125-126).

Mesmo que as questões ligadas ao higienismo e a eugenia fossem voltadas a medidas e preocupações preventivas referentes ao espaço público, como as medidas de saneamento e de repressão a locais considerados vetores de doenças e imoralidades (como cortiços, becos e pensões), podemos supor com certa segurança que estas questões estivessem presentes na Santa Casa de Misericórdia, uma vez que, por mais que a instituição tenha gradativamente adquirido funções terapêuticas e de produção de conhecimento médico (principalmente no início do século XX), como destaca Beatriz Weber (1999, p. 176), ela era uma instituição marcada por suas funções assistenciais ${ }^{5}$. Mais do que um local para o tratamento terapêutico de enfermidades, a Santa Casa era vista por muitos populares e miseráveis, como um lugar a recorrer para receber cuidados relativos à alimentação e a higiene. Nesse sentido, o grande fluxo de indivíduos pertencentes às "classes perigosas" e moradores de locais insalubres nas dependências da Misericórdia, poderia despertar o interesse dos membros da instituição pelas questões eugenistas e de higienismo.

\section{A enferma e negra polícia de Porto Alegre}

Retornando aos indivíduos engajados nas instituições de controle urbano, através da análise dos registros retirados dos livros $n^{\circ} 6$ e 7 de Matrícula Geral dos Enfermos da Santa Casa de Misericórdia de Porto Alegre (que compreendem o período de 1888 a 1894) é possível obter alguns dados importantes sobre os policiais da capital gaúcha, uma vez que até 1906 (ano da inauguração do Hospital Militar de Porto Alegre) a Santa Casa era responsável pelo atendimento dos praças da Brigada Militar em uma área específica destinada a eles, sendo assim é abundante o número de praças, militares e policiais encontrados nos livros. Os registros encontrados passaram pela transcrição paleográfica e posterior indexação em um banco de dados de Excel. No total foram transcritos 11026 registros, dentre estes 3185 referiam-se a guardas cívicos, municipais ou policiais que em algum momento procuraram os serviços da Santa Casa. Destes 3185 registros apenas 36 não trazem a referência de cor do indivíduo. Alguns policiais foram internados por mais de uma vez na instituição, optei por subtrair as internações reincidentes e então obtive 1.970 registros dos quais se pode analisar dados referentes à faixa etária, estado civil, questão étnicoracial, bem como a saúde e a doença.

\begin{tabular}{|c|c|c|}
\hline Ano & $\begin{array}{l}\text { Número Total de } \\
\text { Registros }\end{array}$ & $\begin{array}{l}\text { Policiais/ Guardas Cívicos/ } \\
\text { Guardas Municipais }\end{array}$ \\
\hline 1888 & 551 & 98 \\
\hline 1889 & 1209 & 176 \\
\hline 1890 & 1650 & 328 \\
\hline 1891 & 1965 & 449 \\
\hline 1892 & 1894 & 817 \\
\hline 1893 & 2014 & 859 \\
\hline 1894 & 1743 & 458 \\
\hline Total & 11026 & 3185 \\
\hline \multicolumn{3}{|c|}{$\begin{array}{l}\text { Quadro 1-Número de policiais registrados nos livros de Matrícula } \\
\text { Geral dos Enfermos da Santa Casa de Misericórdia de Porto Alegre } \\
\text { por ano. }\end{array}$} \\
\hline
\end{tabular}

\footnotetext{
${ }^{5}$ Beatriz Weber (1999, p. 177) salienta que "até os últimos anos do século XIX a Santa Casa apresentou caráter marcadamente assistencial nas suas diversas atividade". Foi apenas a partir de 1898, com a organização da Faculdade de Medicina, dentro da instituição, que "passou a haver uma maior presença de médicos em Porto Alegre".
} 
No quadro 1 podemos observar o aumento do número de internações de policiais a partir de 1890 , uma das hipóteses para este crescimento é o próprio aumento do número de funcionários da instituição policial que passa a ganhar mais importância no período em questão. Paulo Moreira (2009, p. 33) salienta que houve um aumento significativo no contingente policial nesse período passando de 426 membros em 1857 a 799 nos anos de 1888 e 1889 , representando um crescimento de 87,6\%. Quanto ao aumento significativo de internações de policiais nos anos de 1892 e 1893, não me parece que este aumento tenha alguma relação com a guerra civil (1893-1895), uma vez que as moléstias mais recorrentes nesse período são as do sistema digestivo (como embaraço gástrico) e as doenças venéreas, que sempre estiverem presentes nos anos anteriores como as enfermidades mais recorrentes, enquanto o número de internações por ferimentos por arma de fogo ou armas brancas (que poderia ter relação com a guerra) é pouco significativo em comparação com as demais moléstias, como pode ser visto no quadro 3.

Ao analisar a variável cor me deparei com um pequeno "problema". Em alguns casos o mesmo indivíduo apresentou denominações de cor distintas em diferentes internações. Como exemplo há o guarda cívico Hildebrando Pereira Gomes que em 17 de julho e 04 de novembro de 1892 foi registrado como indiático e em 05 de fevereiro de 1893 foi registrado como caboclo. Apesar dessa heterogeneidade de alguns casos não podemos considerar isto como um empecilho para a análise, uma vez que as diferentes "cores" designadas para um mesmo paciente evidenciam como algumas delas eram consideradas similares no período, como indiática e cabocla. Dessa forma, considerando estes casos peculiares, ou seja, os casos em que um mesmo indivíduo apresenta mais de uma referência de cor, obtive o total de 2009 registros, dentre os quais há uma grande variedade de cores, como parda, indiática, morena, e fula.

\begin{tabular}{|l|c|c|}
\hline Nada consta/ignorado & 36 & $1,80 \%$ \\
\hline Branca & 633 & $31,50 \%$ \\
\hline China & 2 & $0,09 \%$ \\
\hline Fula & 2 & $0,09 \%$ \\
\hline Índia & 6 & $0,30 \%$ \\
\hline Indiática & 63 & $3,14 \%$ \\
\hline Morena & 165 & $8,22 \%$ \\
\hline Mulata & 287 & $0,09 \%$ \\
\hline Parda & 353 & $17,29 \%$ \\
\hline Preta & $\mathbf{2 0 0 9}$ & $\mathbf{1 0 0} \%$ \\
\hline Total & & $22,90 \%$ \\
\hline
\end{tabular}

Quadro 2-Cores dos policiais registrados nos livros de Matrícula Geral dos Enfermos da Santa Casa de Misericórdia de Porto Alegre (1888 a 1894).

Podemos notar no quadro 2 a variedade de denominações étnico-raciais diferentes adotadas nos registros, são 10 designações diferentes para as cores dos pacientes. Se considerarmos que no período em questão, marcado pelo forte racismo, apenas os brancos eram totalmente livres de discriminação racial, salta aos olhos o elevado número de não brancos entre os policiais internados na Santa Casa. Se somarmos todos os indivíduos registrados como pretos, pardos, morenos, indiáticos, índios, entre outros, temos um número absolutamente mais elevado, cerca de $68 \%$, que o de bran$\cos (32 \%)$. Outro fator que chama a atenção é a presença de um africano trabalhando como policial no final do século XIX em Porto Alegre. O registro em questão é o de José Braz, preto, solteiro, 65 anos, guarda cívico, natural da África, com profissão anterior registrada como cozinheiro. Ele deu entrada na Santa Casa em 11 de novembro de 1892 para o tratamento de uma enfermidade cardíaca. Se pensarmos que o último desembarque ilegal de escravos da África para o Rio Grande do Sul 
ocorreu em 1852, existem algumas possibilidades que podem ser cogitadas sobre José, que possivelmente veio para o Brasil muito jovem (ou em algum destes últimos desembarques) sob o jugo da escravidão e se inseriu, após 1888, no serviço policial como uma alternativa de ascensão social.

O elevado número de não brancos entre os policiais de Porto Alegre pode significar umas das poucas possibilidades de inserção no mercado de trabalho para essa parte da população em um momento fortemente marcado pelo racismo. Isto porque, como não havia muitos atrativos no serviço policial (baixa remuneração, carga horária de trabalho elevada, entre outros $)^{6}$, as exigências para o ingresso eram poucas, sendo um trabalho de acesso relativamente fácil inclusive para a população socialmente marginalizada. Além disso, podemos pensar que o ingresso no serviço policial poderia significar uma possibilidade de ascensão social e uma forma de defesa do negro em uma sociedade racista, já que a farda representava autoridade e importância. Paulo Moreira comenta que, ainda no período escravista, muitos escravos fugidos ou libertos, procuravam se alistar na polícia para encobrir sua fuga ou algum crime do passado: "[...] muitos indivíduos usaram tanto o Exército como a Polícia como refúgio; o alistamento podia encobrir a condição de cativo ou um passado criminoso. O fardamento era um símbolo de poder" (MOREIRA, 2009, p. 67, grifo meu). O serviço policial como "via de inclusão social" para a população negra também é destacado por André Rosemberg: “[...] mais importante que o dinheiro minguado, para os po- bres e, principalmente, para os não-brancos, muitos deles ex-escravos, o engajamento podia significar a entrada no mundo oficial, do reconhecimento, de uma certa dose de cidadania: uma importante via de inclusão social.” (ROSEMBERG, 2008, p. 137).

O elevado número de negros e pardos na polícia de Porto Alegre comprova que esta instituição era formada por populares como alguns pesquisadores já haviam afirmado, entretanto, atribuir uma referência étnicoracial para estes indivíduos abre a possibilidade de se discutir futuramente uma importante questão: como esses policiais não brancos lidavam com a autoridade a eles atribuídas no momento de reprimir outros negros e pardos considerados perigosos para o bem-estar social? Um futuro cruzamento com fontes como processos criminais podem responder essa questão. Contudo, a relação desses policiais com outro grupo social da capital pode ser sugerida através da documentação da Santa Casa.

Algumas pesquisas, como a dos já citados Cláudia Mauch e André Rosemberg, mostram que a presença de policiais em documentos que relatam desordens e brigas em botequins e bordéis é constante: "Os soldados e policiais, sejam eles praças da Brigada Militar, do Exército, da Guarda Nacional ou da polícia municipal, são frequentemente (sic) citados como protagonistas de desordens em botequins" (MAUCH, 2004, p. 92-93). A autora ressalta que entre os principais motivos que desencadeavam as brigas entre soldados e civis estavam a disputa pela atenção de alguma mulher ou o estado de embriaguez dos envolvidos. Nos registros levantados

\footnotetext{
${ }^{6}$ Um dos poucos atrativos do trabalho na polícia era o baixo salário dos agentes. De acordo com Cláudia Mauch (2011, p. 130) em 1896 os agentes suburbanos da polícia recebiam apenas 1:080\$000. Cristiana Schettini Pereira (2002, p. 47), ao analisar as relações entre policiais e meretrizes no Rio de Janeiro nas primeiras décadas da República, comenta que enquanto as prostitutas "de janela" cobravam em média $5 \$$ de um cliente comum, "os praças da Brigada Policial ganhavam uma diária que não passava de $3 \$ 900$, menos que um aprendiz de pedreiro. E as condições de trabalho estavam longe de ser satisfatórias. Tinham que morar nos quartéis, submeter-se à disciplina militar, e fazer rondas de 12 horas em dois quartos alternados. Os guardas civis não estavam em situação melhor" ganhando cerca de $3 \$$ de diária além de ter que pagar o fardamento do próprio bolso, de forma que "as tais 'rameiras de baixo estofo' pareciam ter uma situação financeira muito melhor que a dos policiais". Ver: PEREIRA, Cristiana Schettini. Que tenhas teu corpo: uma história social da prostituição no Rio de Janeiro das primeiras décadas republicanas. Campinas, Universidade Estadual de Campinas, 2002, Tese (doutorado).
} 
na documentação da Santa Casa não são raras as internações ocasionadas por ferimentos de arma branca, arma de fogo, entre outros, que podem ter sido gerados em brigas, além de casos de alcoolismo ou doenças que derivam do uso abusivo e frequente do álcool.

\begin{tabular}{l|c|c}
\multicolumn{1}{c}{ Enfermidade } & 659 & $20,69 \%$ \\
\hline Doenças do sistema digestivo & 652 & $20,47 \%$ \\
\hline Doenças do sistema respiratório & 440 & $13,82 \%$ \\
Doenças infectocontagiosas & 394 & $12,37 \%$ \\
\hline Doenças Venéreas & 200 & $6,27 \%$ \\
\hline Doenças da pele e do tecido celular subcutâneo & 205 & $6,43 \%$ \\
\hline Doenças reumáticas & 157 & $4,93 \%$ \\
\hline Ferimentos por violência/acidentes & 151 & $4,75 \%$ \\
\hline Mal definida & 91 & $2,86 \%$ \\
\hline Doenças linfáticas & 88 & $2,76 \%$ \\
\hline Doenças do sistema nervoso & 30 & $0,94 \%$ \\
\hline Doenças do sistema circulatório & 26 & $0,81 \%$ \\
\hline Doenças do sistema urinário & 5 & $0,16 \%$ \\
\hline Alcoolismo & $\mathbf{3 1 8 5}$ & $\mathbf{1 0 0 \%}$ \\
\hline Não tem moléstia/ nada consta & & $2,74 \%$ \\
\hline Total & & \\
\hline
\end{tabular}

Quadro 3-Enfermidades dos policiais registrados nos livros de Matrícula Geral dos Enfermos da Santa Casa de Misericórdia de Porto Alegre (1888 a 1894)

O elevado número de doenças venéreas encontradas nos registros (394 casos) evidencia uma possível relação dos policiais com prostitutas, que seria comum no cotidiano desses indivíduos. Dentre as doenças venéreas encontradas, as mais recorrentes são os cancros venéreos, gonorreia (ou blenorragia) e sífilis, juntas elas somam mais de $80 \%$ das enfermidades classificadas como venéreas. Uma questão importante levantada por Daniel Oliveira (2010) refere-se à concepção religiosa da Santa Casa, marcada por preceitos católicos. Se para a sociedade, no geral, as doenças sexualmente transmissíveis eram vistas como um sinal de degeneração social neste período, para uma instituição religiosa, a imagem que essas enfermidades passavam era ainda pior, estando, segundo Oliveira (2010, p. 53), diretamente ligadas à noção de pecado. Dessa forma, o autor salienta que a vergonha dos enfermos acometidos por essas doenças era ainda maior quando se tratava pela procura de atendimento na Santa Casa, uma instituição religiosa. Segundo ele "os enfermos venéreos evitariam expor as suas marcas do pecado em uma instituição de saúde marcada pelos cânones católicos" $(2010$, p. 53, grifo do autor). Dessa forma, é possível que a incidência dessas doenças, vistas como imorais, fosse ainda maior entre os policiais de Porto Alegre, uma vez que é provável que muitas vezes os mesmos não procurassem atendimento na instituição, por vergonha, e optassem por se tratar em casa ou com métodos alternativos de cura.

Apesar do número significativo de enfermidades de outras naturezas (como respiratórias e digestivas) encontradas nos registros, me detive, neste artigo, a discorrer apenas aquelas doenças ligadas ao estigma da imoralidade e da degeneração $\operatorname{social}^{7}$ no período em questão:

[...] as ideias sobre degeneração foram também associadas a algumas doenças, principalmente às moléstias infecciosas e hereditárias, e é claro, aos seus enfermos. Estes poderiam, por sua vez, terem ligações com as classes perigosas, com os locais inadequados de sobrevivência, com as condutas morais duvidosas, e mais, estarem ligadas ao desregramento sexual e ao excesso. Assim, as doenças

\footnotetext{
${ }^{7}$ Daniel Oliveira ressalta que no final do séc. XIX o pensamento social e científico era baseado nos ideais de degeneração social. Segundo o autor (2010, p. 50-51) o significado para o termo foi dividido em dois pressupostos no período em questão: o primeiro, onde o ser humano era reconhecido como entidade simultaneamente física e moral; e o segundo que acreditava que não só as características físicas, mas também as morais seriam transmitidas de forma hereditária; dessa forma, a loucura e a tendência ao crime, por exemplo, seriam problemas transmitidos de pai para filho e se agravariam cada vez mais na linha sucessória.
} 


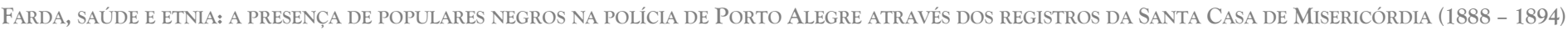

venéreas, infecto-contagiosas e hereditárias transmitiriam aos seus enfermos não só o enfraquecimento físico, mas também o estigma desmoralizante. (OLIVEIRA, 2010, p. 51)

As considerações feitas neste artigo fazem parte de um trabalho ainda em desenvolvimento, onde os registros da Santa Casa de Misericórdia de Porto Alegre serão cruzados com outras fontes como os regulamentos e relatórios de polícia bem como os processos criminais com a intenção de compreender a inserção dos populares, sobretudo negros, nos mecanismos de controle social como forma de ascensão social, inserção no mercado de trabalho e alternativa de resistência ao racismo científico do período, analisando diversos âmbitos da vida destes indivíduos, como saúde/doença, nacionalidade, relações familiares e interações do cotidiano relacionadas ás visões de moralidade e criminalidade na cidade de Porto Alegre.

Neste artigo foi possível perceber, primeiramente, a potencialidade da fonte utilizada, que permite analisar diversos dados a respeito dos populares da capital, que possibilitam ao pesquisador explorar diversos temas diferentes como gênero, trabalho, distribuição espacial, entre outros. O presente trabalho apresenta apenas uma das diversas possibilidades de pesquisa e análise que podem ser feitas com a documentação da Santa Casa de Misericórdia de Porto Alegre, mas que já representa um pequeno ensaio sobre os policiais da cidade, suas características e hábitos de vida, em um momento onde o controle social e a manutenção da ordem representavam uma das principais preocupações das elites e do governo republicano.

\section{Referências bibliográficas}

BRETAS, Marco Luiz. Ordem na cidade: o exercício cotidiano da autoridade policial no Rio de Janeiro, $1907-$ 1930. Rio de Janeiro: Rocco, 1997.

BRETAS, Marcos Luiz; ROSEMBERG, André. A história da polícia no Brasil: balanço e perspectivas. Revista Topoi, v. 14, n. 26, 2013, p. 162-173.

CASTRO, Hebe Maria Mattos de. Das Cores do Silêncio. Os significados da liberdade no sudeste escravista (Brasil - século XIX). Rio de Janeiro, Prêmio Arquivo Nacional de Pesquisa, 1995.

CHALHOUB, Sidney. Cidade Febril: Cortiços e epidemias na corte imperial. São Paulo: Companhia das Letras, 1996.

HOCHMAN, Gilberto; LIMA, Nísia Trindade. Pouca saúde e muita saúva: Sanitarismo, interpretações do país e ciências sociais. In: HOCHMAN, Gilberto (org). Cuidar, controlar, curar: ensaios históricos sobre saúde e doença na América Latina e Caribe. Rio de Janeiro: Editora Fiocruz, 2004, p. 493-525.

MARTINS, Marcelo Thadeu Quintanilha. A civilização do delegado: Modernidade, polícia e sociedade em São Paulo nas primeiras décadas da República, 1889-1930. São Paulo, Tese (Doutorado), Universidade de São Paulo, 2012.

MAUCH, Cláudia. Considerações sobre a história da polícia. Métis: história e cultura, v. 6, n. 11, 2007, p. 107119.

Dizendo-se autoridade: polícia e policiais em Porto Alegre, 1896-1929. Porto Alegre, PPGH/Universidade Federal do Rio Grande do Sul, 2011.

. Ordem Pública e moralidade: imprensa e policiamento urbano em Porto Alegre na década de 1890. Santa Cruz do Sul: EDUNISC/ANPUH-RS, 2004. 
MOREIRA, Paulo Roberto Staudt. Entre o Deboche e a Rapina. Os cenários sociais da criminalidade popular em Porto Alegre. Porto Alegre: Armazém Digital, 2009.

OLIVEIRA, Daniel. Entre Prazeres e Doenças: Enfermos venéreos na sociedade porto-alegrense de fins do século XIX. Revista do Corpo Discente do PPG-História da UFRGS, v. 3, n. 6, 2010, p. 47-71.

PESAVENTO, Sandra Jatahy. O cotidiano da República. Porto Alegre: Editora Universidade/UFRGS, 1990.

ROSEMBERG, André. Polícia, policiamento e o policial na província de São Paulo, no final do Império: a instituição, prática cotidiana e cultura. São Paulo, Tese (Doutorado), Universidade de São Paulo, 2008.

SCHWARCZ, Lilia Moritz. O Espetáculo das raças: cientistas, instituições e questão racial no Brasil 1870 1930. São Paulo: Companhia das Letras, 1993.

SILVEIRA, Eder. A cura da raça: eugenia e higienismo no discurso médico sul-riograndense nas primeiras décadas do século XX. Passo Fundo: Ed. Universidade de Passo Fundo, 2005.

SOUZA, Luis Antônio Francisco de. Lei, cotidiano e cidade: polícia civil e práticas policiais na São Paulo Republicana (1890-1930). São Paulo: IBCCRIM, 2009.

WEBER, Beatriz Teixeira. As artes de curar: medicina, religião, magia e positivismo na República Rio-grandense - 1889-1928. Santa Maria. UFSM, 1999. 